\title{
Nurses Adherence to the National Standards of Patient Safety
}

\author{
RAGHDA E. ABDEL-LATIF, B.N.Sc.; NEHAD F. EZZ ELDEN, D.N.Sc. and EMAN E. ABDEL-ALIM, D.N.Sc. \\ The Department of Nursing Administration, Faculty of Nursing, Cairo University, Egypt
}

\begin{abstract}
Background: Patient safety is the foundation of good patient care, the avoidance and prevention of patient injuries or adverse events resulting from the processes of health care delivery.

Aim of the Study: To assess the nurses' adherence to the national standards of patient safety.

Subjects and Methods: A descriptive design was used to achieve the aim of the current study. A convenient sample of 48 nurses were participated in the current study. The current study was conducted at all the surgical units in Port Said Governorate Hospitals. The required data was collected through: patient safety standards observation check list.

Results: The study's results revealed that, nurses in the study were adhered mostly to the standards of Eliminating Wrong-Site, Wrong-Patient, Wrong-Surgical Procedure and improving effective communication among health care workers. In addition, there was statistically significance correlation between nurses' adherence to national standards of patient safety and their workload during some shifts and there was no correlation between nurses' adherence to national standards of patient safety and their average age.

Conclusion: The present study concluded that the nurses at Port Said governorate hospitals did not adhere to all the national standards of patient safety. Moreover, the nurses in hospital $\mathrm{C}$ adhere to the standards. Also, the highest percentage of nurses' adherence to the national standards of patient safety was observed in the morning shift at all hospitals.

Recommendation: It was recommended that develop strategies to decrease nurse workload, providing enough resources required for adhering to the safety standards and Increase level of administrative supervision on nurses during providing care specially at afternoon and night shifts.
\end{abstract}

Key Words: Nursing adherence - Patient safety standards.

\section{Introduction}

PATIENT safety is the foundation of good patient care. When a member of a family goes into hospital or receive other healthcare then above all the people

Correspondence to: Dr. Raghda E. Abdel-Latif,

The Department of Nursing Administration, Faculty of Nursing, Cairo University want them to be safe. There is something horrifying about being harmed, or indeed causing harm, in an environment of care and trust. People believe that safety is a touchstone and guide to the care that is given to patients. The clinician or the organization that keeps safety to the fore in the midst of many other often competing priorities achieves something remarkable and provides the care that all people want to receive [1].

A lot of definitions for patient safety has emerged from the health care quality movement that is equally abstract, with various approaches to the more concrete essential components. The Patient Safety Group [2]. Defined patient safety as the avoidance and prevention of patient injuries or adverse events resulting from the processes of health care delivery. Patient safety was defined also by World Health Organization [3] as "the prevention of harm to patients.

In another way, Patient safety defined as the prevention of medical error and adverse events (World Health Organization [4]. While, the Institute of Medicine IOM [5] defined safety as "freedom from accidental injury" and patient safety as a discipline or field of inquiry and action has not been fully defined to date in the major consensus statements of the organizations that have propelled its existence.

A standard is the desired quality, quantity, or level of performance that is established as a criterion against which worker's performance will be measured. Also, a standard is the practice among professionals by which the quality of practice, service or education can be judged as a performance model through integrating criteria with norms Basavanthappa [6]

In order to evaluate the safety and the quality of care provided for patients/residents, the Joint Commission establishes National Patient Safety 
Goals annually. Joint Commission [7] identify international patient safety goals (IPSGs) as (1) Improve Accuracy of Patient Identifications, (2) Improve the Effectiveness of Communication among Caregivers, (3) Improve the Safety of HighAlert Medications, (4) Ensure Correct-Patient, Correct-Procedure, and Correct-Site Surgery, (5) Reduce the risk of health care-associated infections, (6) Reduce the risk of patient and resident harm resulting from falls, and finally (7) Prevent health care-associated pressure ulcers.

Nurses are at the center of patient care and therefore are essential drivers of quality improvement. Patient safety remains one of the most critical issues facing health care today and that nurses are the health care professionals most likely to intercept errors and prevent harm to patients Hughes [8]

\section{Significance of the study:}

In 2009, a study of adverse events was carried out in Latin America in 58 hospitals in the following five countries: Argentina, Colombia, Costa Rica, Mexico and Peru. This study estimated that 1 in 10 inpatients will experience a harmful incident during their stay in hospital. These statistics has been recorded in medium and high-income countries, but no analogous statistic currently exists for countries with emerging economies, although it is thought that the extent of the problem in these countries could be even greater. According to estimates, every day 1.4 million people worldwide suffer from an infection acquired in a health-care setting.

In 2005 in Egypt a study of patient safety was performed and disseminated for policy change as a part of regional study within countries in the Eastern Mediterranean region (EMR). It determined the nature and rate of adverse events in 3 hospitals in Cairo through a review of the medical records. Although the recorded adverse event rate was low (ranging from $1 \%$ to $11 \%$, average $6 \%$ ), $34 \%$ of such adverse events were associated with the patient's death and $18 \%$ with permanent disability.

The standards of patient safety are known and published in all Egyptian hospitals but the level of competencies in patient safety is not satisfactory and this study will contribute to minimize the hazards that could occur to patients due to nonadherence to the standards.

\section{Subjects and Methods}

\section{Research design:}

A descriptive designed was utilized for this study to achieve the stated aim.

\section{Setting:}

This study was conducted at three surgical units of the Ministry of Health (MOH) Hospitals at Port Said governorate From June 2016 - Dec. 2016.

\section{Study subject:}

A convenient sample of all staff nurses at surgical units (48) who agreed to participate in the study.

\section{Inclusion criteria:}

All staff nurses with not less than one-month experience in the surgical unit and who are working at surgical units for three shifts (morning, after and night shift) at hospital A, hospital B and hospital $\mathrm{C}$ during the time of the study.

\section{Tool for data collection:}

The required data was collected through the patient safety standards observation check list.

It was developed by the research investigator in Arabic language after reviewing the related literature. The observation check list consists of 73 items derived from 7 main domains as follows: Correct patient identification (9 items), effective communication between care givers ( 7 items), improving usage of high alert medications (16 items), ensuring the right (site of surgery, the correct procedure and the right patient) (5 items), protecting the patient from falling (11 items), reducing the hospital acquired infections through hand washing (15 items) and protecting the patient from bed sores (10 items).

\section{Scoring system:}

3 points Likert scale, with $0-2$ points Likert scale; where $0=$ not met, $1=$ partially met and $2=$ met and where met $=0-1$ deficiencies, partially met $=2$ deficiencies and not met $=3$ or more deficiencies.

\section{Field work:}

Upon receiving the formal written approval was obtained from the ethics and research committee of the faculty of Nursing, Cairo University and the vice dean of Post Graduate Studies and research at the Faculty of Nursing, Cairo University, and the approval of from the three general medical directors of the Ministry of Health hospitals; hospital A, hospital B and hospital C, the investigator had a list of all nursing staff members all over the surgical units in the three hospitals from the three nursing directors, then the investigator approached the unit nurse managers of the three units to explain the aim of the study and to obtain their permission to approach the participants at the three shifts. The investigator started to invite separately each par- 
ticipant according to their shift to participate in the study to provide an oral explanation about the purpose, nature of the study to facilitate and control data collection process, and then each participant signed a written informed consent.

To assess staff nurse's adherence to national standards of patient safety during their patient delivery of care, the investigator used the intermittent instantaneous observation to collect data in different shifts and times.

The investigator assessed the nurse adherence in each hospital through completion of one assessment sheet for each two hour from the morning and afternoon shifts and one sheet for each four hours of the night shift. Each sheet including number of patients served in each time of the sheet, number of nurses in the shift and age of each staff nurse working at this shift.

\section{Validity and reliability:}

Content validity was checked by a group of experts who were consulted to identify tool's content and validity, by five experts consisting of four professors from nursing administration department and one professor from medical surgical department in the Faculty of Nursing, Cairo University. Each expert was asked to examine the data collection tool for its content, clarity, warding format, length and overall appearance. Based on experts comment and recommendations some changes had been made at the data collection tool. Regarding reliability, it was measured by using Alpha Cronbach's Coefficient test which was equal to study tool (89\%) for patient safety observation checklist.

\section{Administrative and ethical consideration:}

A primary approval to carry out the current study was obtained from the ethical committee in the Faculty of Nursing, Cairo University. A written consent was obtained from the participants after complete description of the purpose and nature of the study in order to obtain their acceptance as well as to gain their cooperation. Participation in the study is voluntary; each participant has the right to withdrew from the study without any rational. Nurses were assured that these data will not be used in another research without their permission and participation was with no risk for blaming or punishment.

\section{Statistical design:}

Up on completion of data collection, data were tabulated and analyzed using statistical package for social science (SPSS) program version 20. Data were analyzed using descriptive statistics in form of frequency distribution, percentages, mean and standard deviation and differential statistics in the form of ANOVA test, $p$-value, and Chi-square, $p$ value $<0.05$ considered significant.

\section{Results}

Table (1) shows that the highest percentage $(75 \%)$ of the staff nurses were females. While $(25 \%)$ were males. The highest percentage $(31.25 \%)$ of the staff nurses according to age ranged from $40<50$ years old. The highest percentage $(79.17 \%)$ of the staff nurses graduated from Diploma of technical schools of nursing, while $(2.09 \%)$ graduated from Bachelor of nursing. Also, $41.61 \%$ of them had years of experience ranged from 10 $<20$ years. And the highest percentage $(66.67 \%)$ of staff nurses had attended training courses related to patient safety, while the lowest percentage (33.34\%) had never attended any training courses related to patient safety.

Table (1): Percentage distribution of the study participants according to their personal characteristics data $(\mathrm{N}=48)$.

\begin{tabular}{lll}
\hline Variable & No. & $\%$ \\
\hline Gender: & & \\
$\quad$ Male & 12 & 25 \\
Female & 36 & 75 \\
Age: & & \\
$20<25$ & 6 & 12.5 \\
$25<30$ & 13 & 27.09 \\
$30<40$ & 12 & 25 \\
$40<50$ & 15 & 31.25 \\
50 and more & 2 & 4.17 \\
Level of education: & & \\
$\quad$ Diploma of technical & 38 & 79.17 \\
schools of nursing & & \\
$\quad$ Diploma of technical & 9 & 18.75 \\
$\quad$ health nursing institute & & \\
Bachelor of nursing & 1 & 2.09 \\
Years of experience: & & \\
$1>5$ & 8 & 16.67 \\
5<10 & 12 & 25 \\
10<20 & 20 & 41.67 \\
20 and more & 8 & 16.67 \\
Attendance of training courses & & \\
related to patient safety: & & \\
$\quad$ Yes & 32 & 66.67 \\
No & 16 & 33.34 \\
\hline & &
\end{tabular}

Table (2) shows that highest percentage $(71.55 \%)$ of nurses adherence to the standard of eliminating wrong-Site, wrong-Patient, wrongprocedure surgery followed by the percentage $(67.54 \%)$ of the standard of improve effective communication at the three hospitals, while the 
least percentage $(37.39 \%)$ of nurses were adhered to the standard of Reduce the risk of developing pressure ulcers followed by the percentage (38.24\%) were adhered to the standard of reduce the risk of patient harm resulting from falls.

Table (3) illustrates that the highest percentage $(58.16 \%)$ of nurses' adherence to the national standards of patient safety was observed at hospital $\mathrm{C}$, while the least percentage $(48.78 \%)$ was observed at hospital B followed by the percentage (49.99\%) observed at hospital A. Also, the same table shows that there is a close relative percentage of the nurses' adherence to all national standards of patient safety at hospital A and B while there is a distant spaced percentage of adherence between hospital $\mathrm{C}$ and the other two hospitals.

Table (4) shows that the highest percentage $(57.15 \%)$ was observed at the Morning shift of nurses' adherence to the national standards of patient safety, while the least percentage $(45.36 \%)$ of nurses' adherence to the national standards of patient safety was observed at the night shift. Also, the same table shows that there is a close relative percentage of the nurses' adherence to national standards of patient safety at morning shift and afternoon shift while there is a distant spaced percentage of adherence between night shift and the other two shifts.

Table (5) was found statistically significant positive correlation between nurses' adherence to national standards of patient safety and their workload during night shift, and negative correlation during morning shift. Also, there was no statistically significant correlation between nurses' adherence to national standards of patient safety and their workload during afternoon shift.

Table (6) illustrates that there is no statistically significant correlation between nurses' adherence to national standards of patient safety and their average age during afternoon and night shift, while there is a negative correlation during morning shift.

Table (2): Percentage difference of the total nurses' adherence to each national standards of patient safety at the three studied hospitals.

\begin{tabular}{|c|c|c|c|c|c|c|}
\hline Domains & $\begin{array}{l}\text { Hospital A } \\
(\mathrm{N}=24)\end{array}$ & $\begin{array}{l}\text { Hospital B } \\
(\mathrm{N}=12)\end{array}$ & $\begin{array}{l}\text { Hospital C } \\
(\mathrm{N}=12)\end{array}$ & $\begin{array}{c}\text { Total } \\
\text { percentage of } \\
\text { nurses' } \\
\text { adherence } \%\end{array}$ & $\begin{array}{l}\text { Chi- } \\
\text { square }\end{array}$ & $\begin{array}{c}p- \\
\text { value }\end{array}$ \\
\hline Identify Patients Correctly & 24.69 & 47.66 & 54.39 & 42.25 & 1.03 & 0.60 \\
\hline Improve Effective Communication & 61.90 & 73.81 & 66.90 & 67.54 & 0.10 & 0.95 \\
\hline Improve the Safety of High Alert Medications & 53.33 & 49.68 & 74.49 & 59.17 & 0.55 & 0.76 \\
\hline $\begin{array}{l}\text { Eliminate Wrong-Site, Wrong-Patient, } \\
\text { Wrong-Procedure Surgery }\end{array}$ & 82.22 & 56.25 & 76.19 & 71.55 & 0.46 & 0.79 \\
\hline Reduce the Risk of Patient Harm Resulting from Falls & 43.94 & 33.90 & 36.87 & 38.24 & 0.13 & 0.94 \\
\hline Reduce the Risk of Health Care-Acquired Infections & 41.85 & 54.07 & 59.56 & 51.83 & 0.29 & 0.87 \\
\hline Reduce the Risk of developing pressure ulcers & 33.33 & 35.63 & 43.21 & 37.39 & 0.13 & 0.94 \\
\hline
\end{tabular}

Table (3): Total Mean scores percentage of staff nurses' adherence to all national standards of patient safety.

\begin{tabular}{|c|c|c|c|c|c|c|}
\hline \multirow[b]{2}{*}{ Hospital } & \multirow[b]{2}{*}{$\mathrm{N}$} & \multirow{2}{*}{$\begin{array}{l}\text { Percentage of adherence } \\
\text { to all standards }\end{array}$} & \multirow[b]{2}{*}{ Dimension } & & & \multirow[b]{2}{*}{$\begin{array}{c}\text { Night } \\
\text { shift }\end{array}$} \\
\hline & & & & $\begin{array}{l}\text { Morning } \\
\text { shift }\end{array}$ & $\begin{array}{l}\text { Afternoon } \\
\text { shift }\end{array}$ & \\
\hline $\begin{array}{l}\text { Hospital A } \\
\text { Hospital B }\end{array}$ & $\begin{array}{r}24 \\
12\end{array}$ & $\begin{array}{l}49.99 \% \\
48.78 \%\end{array}$ & Percentage of nurses' & $57.15 \%$ & $55.59 \%$ & $45.36 \%$ \\
\hline Hospital C & 12 & $58.16 \%$ & adherence & & & \\
\hline
\end{tabular}

Table (4): Mean percentage of nurses' adherence to national standards of patient safety according to adherence per shift at the three studied hospitals.
Table (5): Correlation between the nurses' adherence to national standards of patient safety at the three studied hospitals per shift and the dimensions of work load.

\begin{tabular}{|c|c|c|c|c|c|c|}
\hline \multirow{2}{*}{ Items } & \multicolumn{2}{|c|}{$\begin{array}{l}\text { Morning } \\
\text { shift }\end{array}$} & \multicolumn{2}{|c|}{$\begin{array}{l}\text { Afternoon } \\
\text { shift }\end{array}$} & \multicolumn{2}{|c|}{$\begin{array}{l}\text { Night } \\
\text { shift }\end{array}$} \\
\hline & $r$ & $p$ & $r$ & $p$ & $r$ & $p$ \\
\hline $\begin{array}{l}\text { Workload } \\
\text { per shoft }\end{array}$ & -0.61 & $0.003 *$ & 0.27 & 0.22 & 0.9 & $0.0001 *$ \\
\hline
\end{tabular}

Table (6): Correlation between the nurses' adherence to national standards of patient safety at the three studied hospitals and average age of nurses per shift

\begin{tabular}{|c|c|c|c|c|c|c|}
\hline \multirow[t]{2}{*}{ Items } & \multicolumn{2}{|c|}{$\begin{array}{c}\text { Morning } \\
\text { shift }\end{array}$} & \multicolumn{2}{|c|}{$\begin{array}{l}\text { Afternoon } \\
\text { shift }\end{array}$} & \multicolumn{2}{|c|}{$\begin{array}{l}\text { Night } \\
\text { shift }\end{array}$} \\
\hline & $r$ & $p$ & $r$ & $p$ & $r$ & $p$ \\
\hline $\begin{array}{l}\text { Average age } \\
\text { of nurses } \\
\text { pre shift }\end{array}$ & -0.76 & $0.0001 *$ & 0.08 & 0.72 & 0.29 & 0.18 \\
\hline
\end{tabular}




\section{Discussion}

Findings of the current study showed that the number of female nurses is more than male nurses (75\%); this may be due to the dominance of females in the nursing profession and the recent involvement of males in nursing. The most dominant average age of the nurses at the study sample was ranged from 40 to 50 years. More than $50 \%$ of the sample participants were diploma nurses that is because that technical schools of nursing and technical nursing institute graduate bigger numbers of nurses than the bachelor programs. Also, most of the study sample had experience ranged from eleven to twenty years, this may be because of the most dominant average age of the nurses at the study sample which ranged from 40 to 50 years. Also, nurses were employed in governmental hospitals after having diploma degree and this may be an indicator of nurses' retention in governmental hospitals.

Regarding to training courses obtained by the study sample, the results indicated that a large number $(66.67 \%)$ of nurses attended training courses related to patient safety. This may be because of the attention of the hospitals and nursing administration to the importance of patient safety training in the elimination of medical errors and malpractice. The nurses' percentage which did not have the chance of training referred to the shortage of staff and the full occupancy of some of the study hospitals that is made leaving the service for educational purposes difficult.

Regarding the nurse' adherence to each national standards of patient safety the current study showed that the standard of "Eliminate Wrong-Site, WrongPatient, Wrong-Surgical Procedure" was found to be the most applied standard. This may be due to the presence of a surgical safety checklist that require a nurse to check all the information related to the patient and his surgical procedure including patient name, type and site of surgery, surgical informed consent, the prophylactic anti biotic given before surgery, patient fasting for the appropriate period of time before surgery and availability of data about supplies required for surgery.

This was consistent with Henneman, et al. [13], who found that $39 \%$ of nurses misidentified the patient and $8 \%$ of nurses in and subsequently gave the medication to the wrong patient. Also, related studies have revealed that the nurse's inadequate knowledge on the use of medications and lack of skills will be directly associated with the occurrence of adverse events Liangrong, et al. [14]
In addition, Lack of knowledge, bad attitudes and poor practices amongst nurses in the prevention and control of infections can lead to hospitalacquired infections Chitimwango $P$ [15]. Nair, et al., [16] assessed knowledge, attitude and practices of hand hygiene among medical and nurses at a tertiary health care centre, found that the majority of nurses had poor knowledge with regard to hand hygiene.

This study also showed that the least applied standard of patient safety by the nurses is the standard of "reducing the risk of developing pressure ulcers". This could be due to lack of adequate resources of air mattress and bed linens and also lack of nursing staff numbers per shift to change the patient position or to give enough education to the patient about bed sores and to do simple exercises especially after surgical operations. These findings were compatible with those of Ball $\mathrm{J}$ et al. [17], who demonstrated that there is a relationship between care left undone and staffing. Also, they found that inadequate resources were consistently identified as the most significant contributing factor to unfinished care.

The next least applied standard by nurses at this study was the standard of reducing the risk of patient harm resulting from falls which could be due to lack of guidance marks that is used to differentiate patients at risk for fall and those who are not and are hanged on the patient's bed and also some beds are without side rails to use to prevent patients from fall and if they are exist the nurses sometimes forget to raise them. Also, the increased number of patients admitted to the unit against number of nurses working per shift so they don't have enough time to assess and reassess the patient condition and his risk for fall or even to help the patients at risk when they move.

This was consistent with Henneman, et al. [13], who found that $39 \%$ of nurses misidentified the patient and $8 \%$ of nurses in and subsequently gave the medication to the wrong patient. Also, related studies have revealed that the nurse's inadequate knowledge on the use of medications and lack of skills will be directly associated with the occurrence of adverse events Liangrong, et al. [14] .

In addition, Lack of knowledge, bad attitudes and poor practices amongst nurses in the prevention and control of infections can lead to hospitalacquired infections Chitimwango $P$ [15]. Nair, et al, [16] assessed knowledge, attitude and practices of hand hygiene among medical and nurses at a tertiary health care centre, found that the majority 
of nurses had poor knowledge with regard to hand hygiene.

This study also showed that the least applied standard of patient safety by the nurses is the standard of "reducing the risk of developing pressure ulcers". This could be due to lack of adequate resources of air mattress and bed linens and also lack of nursing staff numbers per shift to change the patient position or to give enough education to the patient about bed sores and to do simple exercises especially after surgical operations. These findings were compatible with those of Ball $\mathbf{J}$ et al. [17], who demonstrated that there is a relationship between care left undone and staffing. Also, they found that inadequate resources were consistently identified as the most significant contributing factor to unfinished care.

The next least applied standard by nurses at this study was the standard of reducing the risk of patient harm resulting from falls which could be due to lack of guidance marks that is used to differentiate patients at risk for fall and those who are not and are hanged on the patient's bed and also some beds are without side rails to use to prevent patients from fall and if they are exist the nurses sometimes forget to raise them. Also, the increased number of patients admitted to the unit against number of nurses working per shift so they don't have enough time to assess and reassess the patient condition and his risk for fall or even to help the patients at risk when they move.

These findings were consistent with Dykes, et al. [18] who demonstrated that the most effective method used to prevent fall relied heavily on communication to relay high fall risk patients from shift to shift. The problem therein lied with the quality of nursing communication and therefore prevention was ineffective. A powerful tool in fall prevention is the nurses' own experience and intuition, Meyer [19] reported that there was no difference in fall rates with those that used fall risk assessment tools and those that did not and relied on their own judgment. The Cochrane Collaboration, [20].

Surprisingly, this study result is not compatible with Butcher [21], who found that $70 \%$ of falls happened in the day shift (when more staff are on shift) and most of these patients were in fact alert and oriented which contradicts with previous perceptions that suggested that it was the disorientated and 'neglected' (in terms of the amount of staff accessible-such as night and weekend shifts) who are fall prone.
Comparing the results of nurses' adherence to national standards of patient safety between the three studied hospitals, hospital $\mathrm{C}$ was the one that nurses most adhere to the standards. This could be due to the high qualifications of the quality team at this hospital and the accreditation program in which the hospital leadership is committed to which require that the hospital apply all the standards of patient safety as the instructions of $\mathrm{MOH}$ who supervise directly the accreditation process.

These findings are consistent with another study conducted in Copenhagen on 51 units (38 surgical and 13 anesthetic), significantly more accredited units had guidelines in place compared to nonaccredited units which showed that an improvement on the Systematic Development Scale was significantly higher in accredited than in non-accredited units and that reveals the role of accreditation in improving health and patient safety outcomes in hospitals Juul AB et al. [22]. Also, a recent study done in the USA and England hospitals about how organization boards can positively influence quality of care, which found that organization boards of high-quality hospitals used more effective management practices in adhering to quality standards Tsai TC, et al. [23]

In addition, Comparing the results of nurses' adherence to national standards of patient safety at all studied hospitals and the three different working shifts, this study showed that the highest percentage of nurses' adherence to the national standards of patient safety was observed in the morning shift at all hospitals however there is a statistical significant negative correlation between nurses' adherence to national standards of patient safety and workload during morning shift. These findings could be because of the presence of controlling and supervision from different categories of administrators and the quality team at all hospitals at the morning shift however healthcare staff could be less sensitive to the risks when more workers are available.

These results are compatible with a study investigating the effect of combined direct and reflective supervision of medical, nursing and allied health professionals which found improved adherence to acceptability and repeatability criteria for performance of spirometry Gupta S, et al. [24] However, this study is opposing the results of a study on patients with conditions including cardiac, gastrointestinal, pulmonary and renal, managed by directly supervised medical professionals and found that there were no significantly greater health outcomes compared to those managed by unsupervised professionals Couper K, et al. [25]. 
This study also illustrates that there was a statistically significant positive correlation between nurses' adherence to national standards of patient safety and workload during night shift. These results are consistent with A study by James [26] has found that medical error rates, stress or fatigue due to workload among health professionals, inadequate number of nurses and inadequate time spent with patients are the most important issues affecting health sector. On the opposite side, Brewer [27] found that working long shifts; night shifts and rotating shifts as well as mandatory or intentional over time contribute to nurse's fatigue, accidents, and errors and a decrease in patient and nurse wellbeing.

Also, this study illustrates that there is no statistical significant correlation between nurses' adherence to national standards of patient safety and nurses average age during afternoon and night shift, while there is a negative correlation during morning shift. These results could be due to the distribution of nurses with different ages among all working shifts but sometimes the younger nurses worked at morning shift because of the routine rooster which make the morning shift with increased number of young nurses.

These results are matched not with Feroze M., et al. [28] whose study found that most of the nurses were at young age (age group of 26-30 years) and they consider this as an advantage because they are hyper active which is required in critical care units to improve safety of patients after critical procedure such as cardiac catheterization.

\section{Conclusion:}

According to the results of present study, it is concluded that nurses at the Ministry of Health Hospitals of Port Said governorate were moderately adhere to the national standards of patient safety as they highly adhere to two standards which were "Eliminate wrong-site, wrong patient, wrongprocedure surgery" and "improving effective communication among health care workers". Also, they moderately adhere to three standards which were "Identify Patients Correctly" and the standard of "Improve the Safety of High Alert Medications". While they poorly adhered to two standards which were "reducing the risk of developing pressure ulcers" and the standard of "reducing the risk of patient harm". Highest percentage of nurses' adherence to the national standards of patient safety was observed at hospital $\mathrm{C}$ and in the Morning shift. There is a positive correlation between nurses' adherence to national standards of patient safety and their workload during night shift, and negative correlation during morning shift. There was no correlation between nurses' adherence and their workload during afternoon shift. Also, there is no correlation between nurses' adherence to national standards of patient safety and their average age during afternoon and night shift, while there is a negative correlation during morning shift.

\section{Recommendations:}

Based on the results of the current study, it was recommended that:

- Developing strategies to solve the deficiency in the staffing numbers as using part time and on call system to decrease workload.

- Provide enough resources required for adhering to the safety standards.

- Increase level of administrative supervision on nurses during providing care specially at afternoon and night shifts.

- Provide enough training courses about patient safety standards.

- Create a blame-free environment that encourages nurses to report errors.

- Involve all the governorate hospitals in the accreditation program which could improve the quality and safety of patient care.

\section{References}

1- VINCENT C.: Patient Safety, 2 nd edn. Oxford: Wiley Blackwell. 2011.

2- The Patient Safety Group: AHRQ culture survey, 2008.

3- WHO: Word Alliance for Patient Safety: Patients for Patient Safety. Geneva: WHO; [cited 2016 Dec 28], 2010.

4- WHO: Patient safety curriculum guide: Multi-professional edition. (NLM classification: WX 167). Geneva: World Health Organization, 2011.

5- Institute of Medicine (IOM): To err is human: Building a safer health system, National Academy Press. Available at: http://www.nap.edu/ books/0309068371/html/, 2009.

6- B.T. BASAVANTHAPPA: Nursing Administration; 2 nd ed. ch (25) 713-719. Jaypee Brothers Medical Publishers. ISBN: 978-81-8448-697-1, 2009.

7- Joint Commission International a Division of Joint Commission Resources: Joint Commission International Accreditation standards for Hospital. ${ }^{\text {rd }}$ ed. USA: Joint Commission Resources, Inc. (JCR), p 31-3, 2008.

8- HUGHES R.G.: Patient safety and quality: An evidencebased handbook for nurses. (Prepared with support from the Robert Wood Johnson Foundation). AHRQ Publication No. 08-0043. Rockville, MD: Agency for Healthcare Research and Quality, 2008.

9- NAGPAL K., ARORA S., ABBOUDI M., VATS A., WONG H.W., MANCHANDA C., et al.: Postoperative handover: Problems, pitfalls, and prevention of error. Ann. Surg., 252: 171-176, 2010. 
10- THOMASSEN $\varnothing$, BRATTEB $\varnothing$ G., HELTNE J.K., SØFTELAND E. and ESPELAND A.: Checklists in the operating room: Help or hurdle? A qualitative study on health worker's experiences. BMC Health Serv. Res., 10: 342. doi: 10.1186/1472-6963-10-342, 2010.

11-DINNDORF-HOGENSON G.: Moral courage in practice: Implications for patient safety. Journal of Nursing Regulation, 6 (2): 10-16, 2015.

12-MOHAMED R. and TOHAMI S.: Patient Safety: Assessing Nurses' Compliance. J. Am. Sci., 8 (1): 748-755]. (ISSN: 1545-1003), 2012.

13- HENNEMAN P.L., MARQUARD J.L., FISHER D.L., BLEIL J., WALSH B., HENNEMAN J.P., et al.: Barcode Verification: Reducing But Not Eliminating Medication Errors. The Journal of Nursing Administration, 42 (12): 562-566, 2012.

14- LIANGRONG S., JINFENG Y, XIA X. and ZHONGMIN S.: Cognition of high-alert medication knowledge of clinical nurses and improvement measures to eradicate medication errors. Biomedical Research 2018; Special Issue: S370-S373, 2017.

15- CHITIMWANGO P.: Knowledge, Attitudes and practices of nurses in infection prevention and control within a tertiary hospital in Zambia: Stellenbosch University, 2015.

16- NAIR S.S., HANUMANTAPPA R., HIREMATH S.G. and RAGHUNATH P.: Knowledge, attitude and practice of hand hygiene among medical and nursing students at a tertiary health care centre in Raichur, India. ISRN Preventive Medicine, 1-4, 2014.

17- BALL J.E., MURRELLS T., RAFFERTY A.M., MORROW E. and GRIFFITHS P.: 'Care left undone' during nursing shifts: Associations with workload and perceived quality of care. BMJ Quality \& Safety, 23 (2): 116-25, 2014.

18- DYKES P.C., CARROLL D.L., HURLEY A., LIPSITZ S., BENOIT A., CHANG F., MELTZER S., TSURIKOVA R., ZUYOV L. and MIDDLETON B.: Fall Prevention in Acute Care Hospitals: A Randomized Trial.Journal of
American Medical Association, 304 (17): 1912-1918, 2010.

19- MEYER G., KÖPKE S., HAASTERT B. and MÜHLHAUSER I.: Comparison of a Fall Risk Assessment Tool With Nurses' Judgement Alone: A Cluster-Randomised Controlled Trial. Age and Ageing, 38 (4): 417-423, 2009.

20- The Cochrane Collaboration: Interventions for Preventing Falls in Older People in Care Facilities and Hospitals (Review), 2013.

21- BUTCHER, L.: The No-Fall Zone. Hospitals \& Health Networks, 87 (6): 26-30, 2013.

22- JUUL A.B., GLUUD C., WETTERSLEV J., CALLESEN T., JENSEN G., KOFOED-ENEVOLDSEN A. DIPOM Group: The effects of a randomised multi-centre trial and international accreditation on availability and quality of clinical guidelines. Int. J. Health Care Qual Assur Inc Leadersh Health Serv., 18: 321-8, 2005.

23- TSAI T.C., JHA A.K., GAWANDE A.A., et al.: Hospital board and management practices are strongly related to hospital performance on clinical quality metrics. Health Aff (Millwood), 34: 1304-1311, 2015.

24- GUPTA S., MOOSA D., MACPHERSON A., ALLEN C. and TAMARI I.E.: Effects of a 12-month multi-faceted mentoring intervention on knowledge, quality and usage of spirometry in primary care: A before-and-after study. BMC Pulm Med., 16 (1): 56, 2016.

25- COUPER K., KIMANI P.K., ABELLA B.S., CHILWAN M., COOKE M.W., DAVIES R.P., et al.: The systemwide effect of real-time audiovisual feedback and postevent debriefing for in-hospital cardiac arrest: The cardiopulmonary resuscitation quality improvement initiative. Crit Care Med., 43: 2321-31, 2015.

26- JAMSHIDI N., ABBASZADEH A., KALYANI M.N. and SHARIF F.: Effectiveness of video information on coronary angiography patients' outcomes. Collegian, 20 (3): pp. 153-159, 2013.

27- BREWER, K.: How a 'just culture'can improve safety in health care. American Nurse Today, 6 (6), 2011. 


\section{ملى التزام الممرضات بالمعايير القومية السلامة المرضى بالمعايير}

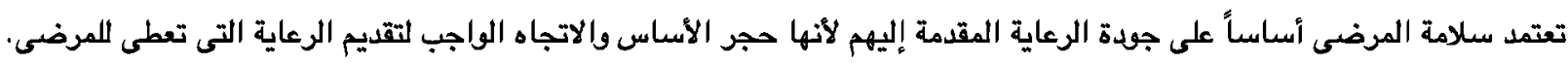

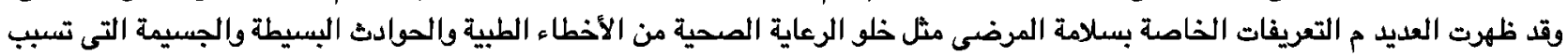
ضرد المريض وقد تؤدى بحياته.

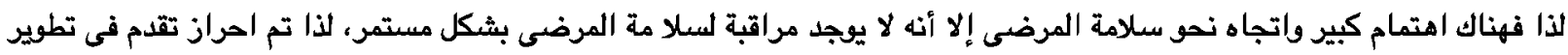

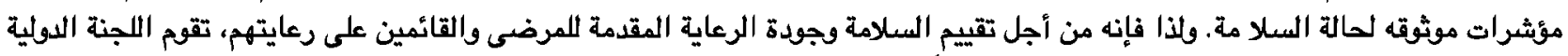

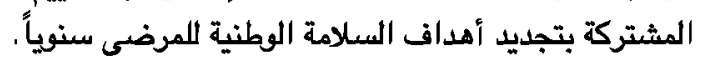

$$
\text { الهدف من الدراسة: تقييم مستوى التزام الممرضات بالمعايير الوطنية لسلامة المرضى. }
$$

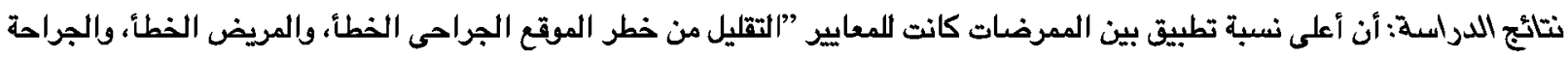

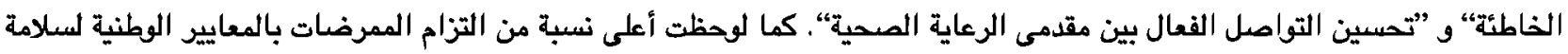

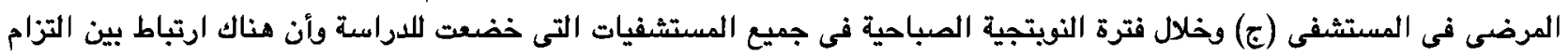

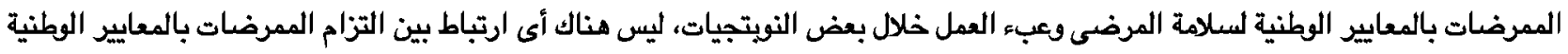

